\title{
PENGARUH DIABETIK SELF MANAGEMENT EDUCATION (DSME) TERHADAP RESIKO TERJADINYA ULCUS DIABETIK
}

\author{
Danur Azissah Roesliana Sofais \\ Program Studi Keperawatan STIKes Dehasen Bengkulu \\ JL. Merapi Raya No.42 Kebun Tebeng Kota Bengkulu \\ d.azissah@yahoo.com
}

\begin{abstract}
The sufferers' incapable in carried out DM type 2 is one of the most caused it. Diabetic SelfManagement Education (DSME) is the method which can stimulate of patients' knowledge; skill and ability in doing the self-care for prevent the ulcers' diabetic. The aim of this research is to find out the influence of DSME toward the risk of consistence of ulcers' diabetic for path treatment's patients of mellitus diabetes (MD) type 2 at Pukesmas Jalan Gedang of Bengkulu's working area in year 2016. The method of this research is quasi-experimental with pre-test and post-test approach. Simple Random Sampling is used to divided the 66 respondent in 2 groups i.e. intervention and control groups. The result showed that the influence of DSME toward risk of consistence of ulcers' diabetic before DSME $(p=0,329)$ whereas, after DSME $(p=0,020)$; with improvement of knowledge before $\operatorname{DSME}(\mathrm{p}=0,135)$, after DSME $(\mathrm{p}=0,027)$; and leg treatment behavior before DSME $(\mathrm{p}=0,135)$ whereas, after DSME $(\mathrm{p}=0,041)$; as well as self-confidence before DSME $(\mathrm{p}=0,454)$ whereas, after DSME $(p=0,002)$ by value $(\leq \alpha=0,05)$. It can conclude that there is a significant influence of DSME toward risk of consistence of ulcers' diabetic for path treatment's patients of mellitus diabetes (MD) type 2 at Pukesmas Jalan Gedang Bengkulu's Working Area in year 2016. This research can be input information for the health's staff. In order, it can give the knowledge and the health promotion about the influence of DSME toward the risk of consistence of ulcers' diabetic.
\end{abstract}

Keywords: Diabetic Self-Management Education (DSME), Ulcers’ Diabetic.

Abstrak: Penderita yang tidak mampu melakukan DM tipe 2 adalah salah satu penyebab paling banyak penyebabnya. Pendidikan Manajemen Diri Diabetik (DSME) adalah metode yang dapat merangsang pengetahuan pasien; keterampilan dan kemampuan dalam melakukan perawatan diri untuk mencegah penderita diabetes 'ulkus'. Tujuan dari penelitian ini adalah untuk mengetahui pengaruh DSME terhadap risiko konsistensi penderita diabetes ulkus terhadap pasien diabetes mellitus tipe pathway di Pukesmas Jalan Gedang di wilayah kerja Bengkulu tahun 2016. Metode ini Penelitian dilakukan dengan eksperimen kuasi eksperimental dengan pendekatan pre-test dan post-test. Simple Random Sampling digunakan untuk membagi 66 responden dalam 2 kelompok yaitu kelompok intervensi dan kontrol. Hasil penelitian menunjukkan bahwa pengaruh DSME terhadap risiko konsistensi diabetes ulkus sebelum DSME $(p=0,329)$ sedangkan setelah DSME $(p=0,020)$; dengan peningkatan pengetahuan sebelum DSME $(\mathrm{p}=0,135)$, setelah DSME $(\mathrm{p}=0,027)$; dan perilaku pengobatan kaki sebelum DSME $(p=0,135)$ sedangkan, setelah DSME $(p=0,041)$; serta kepercayaan diri sebelum DSME $(p=0,454)$ sedangkan, setelah DSME $(p=0,002)$ dengan nilai $(\leq \alpha=0,05)$. Dapat disimpulkan bahwa ada pengaruh DSME yang signifikan terhadap risiko konsistensi penderita diabetes ulkus terhadap pasien diabetes mellitus (MD) tipe 2 di Wilayah Kerja Pukesmas Jalan Gedang Bengkulu pada tahun 2016. Penelitian ini dapat menjadi masukan informasi untuk staf kesehatan Agar dapat memberi pengetahuan dan promosi kesehatan tentang pengaruh DSME terhadap risiko konsistensi penderita diabetes ulkus.

Kata Kunci: Pendidikan Manajemen Mandiri Diabetes (DSME), Ulcers 'Diabetic

Penyakit tidak menular (PTM) menjadi penyebab utama kematian secara global. Data World Health Organization (WHO) menunjukkan bahwa dari 57 juta kematian yang terjadi di dunia pada tahun
2008, sebanyak 36 juta atau hampir dua pertiganya disebabkan oleh Penyakit Tidak Menular. PTM juga membunuh penduduk dengan usia yang lebih muda. Di negaranegara dengan tingkat ekonomi rendah dan 
menengah, dari seluruh kematian yang terjadi pada orang-orang berusia kurang dari 60 tahun, 29\% disebabkan oleh PTM, sedangkan di negara-negara maju, menyebabkan $13 \%$ kematian. Proporsi penyebab kematian PTM pada orang-orang berusia kurang dari 70 tahun, penyakit cardiovaskular merupakan penyebab terbesar (39\%), diikuti kanker (27\%), sedangkan penyakit pernafasan kronis, penyakit pencernaan dan PTM yang lain bersama-sama menyebabkan sekitar $30 \%$ kematian, serta 4\% kematian disebabkan Diabetes Mellitus (WHO, 2011).

Diabetes Mellitus adalah gangguan metabolisme yang secara genetis dan klinis termasuk heterogen dengan manifestasi berupa hilangnya toleransi karbohidrat. Dampak akibat penyakit diabetes melitus memang tidak boleh kita anggap remeh. Diabetes Mellitus jika tidak dikelola dengan baik, dapat menyebabkan komplikasi pada seluruh organ tubuh, dari kepala sampai kaki, kesemua tempat dimana yang kadar glukosa tinggi tersebut mengalir (Pranadji, 2007). Perkiraan jumlah pasien Diabetes Mellitus tipe 2 di dunia pada tahun 2010 sebanyak 285 juta jiwa dari total populasi dunia sebanyak 7 miliar jiwa dan meningkat sebanyak 439 juta jiwa pada tahun 2030 dari total populasi dunia sebanyak 8,4 miliar jiwa. Berdasarkan data dari Badan Pusat Statistik (BPS) di Indonesia jumlah penyadang diabetes pada tahun 2003 sebanyak 13,7 juta orang dan berdasarkan pola pertambahan penduduk diperkirakan pada 2030 akan ada 20,1 juta penyandang DM dengan tingkat prevalensi 14,7 persen untuk daerah urban dan 7,2 persen di rural. Organisasi Kesehatan Dunia (World Health Organisation, WHO) memprediksi kenaikan jumlah penyandang DM di Indonesia dari 8,4 juta pada tahun 2000 menjadi sekitar 21,3 juta pada tahun 2030 (Pusat Data dan Informasi PERSI, 2012).

Menurut cacatan Dinas Kesehatan Kota bengkulu dengan total keseluruhan Wilayah Kerja Puskesmas pada tahun 2012 menunjukan bahwa penderita Diabetes Mellitus di bengkulu sebanyak 1,149 orang penderita, pada tahun 2013 terdapat 1,057 orang penderita, pada tahun 2014 terdapat 741 orang penderita (Dinkes bengkulu 2014), salah satunya terdapat di Pukesmas Jalan Gedang terbanyak kasus Diabetes Mellitus pada tahun 2014 dengan 153 orang penderita, sedangkan data statistik yang diperoleh sementara dari Wilayah Kerja Puskesmas Jalan Gedang Bengkulu pada tahun 2015 dari bulan januari sampai oktober sebanyak 194 kasus penderita Diabetes Mellitus. Salah satu upaya untuk meningkatkan derajat kesehatan adalah dengan cara menurunkan jumlah penyakit yang dapat menimbulkan masalah kesehatan yang berdampak pada produktivitas dan dapat menurunkan sumber daya manusia seperti Diabetes Mellitus. Salah satu bentuk edukasi yang umum digunakan dan terbukti efektif dalam memperbaiki hasil klinis dan kualitas hidup pasien Diabetes Mellitus tipe 2 adalah Diabetik Self Management Education (DSME). DSME adalah suatu proses berkelanjutan yang dilakukan untuk memfasilitasi pengetahuan, keterampilan, dan kemampuan pasien DM untuk melakukan perawatan mandiri (Funnel, 2008). Berdasarkan hasil survei awal di Wilayah Kerja Puskesmas Jalan Gedang Bengkulu 2015 pada 10 penderita Diabetes Mellitus, dimana 7 orang diantaranya baru mengalami resiko ulkus diabetes dan 3 orang terkena ulkus diabetik. sehingga menunjukkan bahwa perawat tidak pernah memberikan Diabetes Self Management Education (DSME) kepada pasien Diabetes Mellitus Type 2 karena keterbatasan waktu, dan banyaknya pasien Diabetes Mellitus Type 2 yang kontrol di Puskesmas Jalan Gedang.

Berdasarkan uraian diatas dan kondisi tersebut peneliti bermaksud untuk melakukan penelitian tentang pengaruh Diabetik Self Management Education (DSME) terhadap Resiko Terjadinya Ulkus Diabetik pada Pasien Rawat Jalan Diabetes 
Mellitus (DM) Type 2 di Wilayah Kerja Pukesmas Jalan Gedang Bengkulu tahun 2016.
BAHAN DAN CARA KERJA

Jenis penelitian ini menggunakan quasi-experimental atau eksperimen semu dengan pendekatan the one gruop pre-post test design.

\section{HASIL}

Tabel 1. Distribusi Karakteristik Umum Responden dan Uji Homogenitas pada Kelompok Perlakuan dan Kelompok Kontrol

\begin{tabular}{|c|c|c|c|c|}
\hline \multirow[t]{2}{*}{ Variabel } & \multirow[t]{2}{*}{ Katagori } & \multicolumn{2}{|c|}{ Kelompok } & \multirow[t]{2}{*}{$\mathbf{P}$} \\
\hline & & Perlakuan & Kontrol & \\
\hline \multirow[t]{3}{*}{ Kelompok Umur } & $40-49$ & 1 & 8 & \multirow{3}{*}{0,767} \\
\hline & $50-59$ & 19 & 16 & \\
\hline & $\geq 60$ & 13 & 9 & \\
\hline \multirow[t]{2}{*}{ Jenis Kelamin } & Laki laki & 9 & 24 & \multirow{2}{*}{0,049} \\
\hline & Perempuan & 13 & 20 & \\
\hline \multirow[t]{3}{*}{ Tingkat Pendidikan } & Tinggi & 3 & 4 & \multirow{3}{*}{0,752} \\
\hline & Menengah & 8 & 15 & \\
\hline & Rendah & 22 & 14 & \\
\hline \multirow{2}{*}{ Sosial Ekonomi } & $\leq 1.500 .000$ & 19 & 20 & \multirow{2}{*}{0,628} \\
\hline & $>1.500 .000$ & 14 & 13 & \\
\hline \multirow[t]{2}{*}{ Lama Menderita DM } & $>3$ tahun & 30 & 28 & \multirow{2}{*}{0,135} \\
\hline & $\leq 3$ tahun & 3 & 5 & \\
\hline \multirow[t]{2}{*}{ Komplikasi Penyakit DM } & Tidak ada komplikasi & 16 & 11 & \multirow[b]{2}{*}{0,053} \\
\hline & Ada komplikasi & 17 & 22 & \\
\hline \multirow[t]{2}{*}{ Jenis Terapi } & Ada jenis therapy & 16 & 19 & \multirow{2}{*}{0,418} \\
\hline & Tidak ada jenis terapi & 17 & 14 & \\
\hline
\end{tabular}

Tabel 2. Distribusi Pengetahuan Responden tentang Perawatan Kaki Uji Homogenitas pada Kelompok Perlakuan dan Kelompok Kontrol Pre dan Post

\begin{tabular}{|c|c|c|c|c|c|c|c|c|}
\hline \multirow{2}{*}{$\begin{array}{l}\text { Pengetahuan tentang } \\
\text { Perawatan Kaki }\end{array}$} & \multicolumn{3}{|c|}{ Pre } & & \multicolumn{3}{|c|}{ Post } & \multirow[t]{2}{*}{ P Value } \\
\hline & Mean & Min & Max & P Value & Mean & Min & $\operatorname{Max}$ & \\
\hline \multirow{2}{*}{$\begin{array}{l}\text { Kelompok Perlakuan } \\
\text { Kelompok Kontrol }\end{array}$} & 5 & 1 & 9 & \multirow[b]{2}{*}{0,135} & 6 & 3 & 9 & \multirow[b]{2}{*}{0,027} \\
\hline & 5 & 2 & 8 & & 6 & 4 & 9 & \\
\hline
\end{tabular}

Berdasarkan tabel 2. perbedaan pengetahuan responden tentang perawatan kaki dan uji homogenitas pada kelompok perlakuan dan kelompok kontrol sebelum DSME dengan nilai $\mathrm{P}=0,135>\alpha(0,05)$, sedangkan setelah DSME dengan nilai $\mathrm{p}=0,027<\alpha(0,05)$. Artinya ada perbedaan atau pengaruh DSME terhadap pengetahuan tentang perawatan kaki deabetic.

Tabel 3. Distribusi Perilaku Responden tentang Perawatan Kaki Uji Homogenitas pada Kelompok Perlakuan dan Kelompok Kontrol Pre dan Post

\begin{tabular}{lcccccccc}
\hline $\begin{array}{l}\text { Perilaku tentang Perawatan } \\
\text { Kaki }\end{array}$ & Mean & $\begin{array}{c}\text { Pre } \\
\text { Min }\end{array}$ & Max & P Value & Mean & $\begin{array}{c}\text { Post } \\
\text { Min }\end{array}$ & Max & P Value \\
\hline $\begin{array}{l}\text { Kelompok Perlakuan } \\
\text { Kelompok Kontrol }\end{array}$ & 3 & 0 & 5 & & 3 & 1 & 5 & 0,041 \\
& 2 & 1 & 4 & & 3 & 1 & 4 & \\
\hline
\end{tabular}

Berdasarkan tabel 3. perbedaan perilaku responden tentang perawatan kaki dan uji homogenitas pada kelompok perlakuan dan kelompok kontrol sesudah 
DSME dengan nilai $\mathrm{P}=0,135>\alpha(0,05)$, sedangkan setelah DSME dengan nilai $\mathrm{p}=0,041<\alpha(0,05)$. Artinya ada perbedaan atau pengaruh DSME terhadap pengetahuan tentang perawatan kaki deabetic.

Tabel 4. Distribusi Efikasi Diri Responden tentang Resiko Terjadinya Ulcus Uji Homogenitas pada Kelompok Perlakuan dan Kelompok Kontrol Pre dan Post

\begin{tabular}{lcccccccc}
\hline $\begin{array}{l}\text { Efikasi Diri tentang Resiko } \\
\text { Terjadinya Ulcus }\end{array}$ & Mean & $\begin{array}{c}\text { Pre } \\
\text { Min }\end{array}$ & Max & P Value & Mean & $\begin{array}{c}\text { Post } \\
\text { Min }\end{array}$ & Max & P Value \\
\hline $\begin{array}{l}\text { Kelompok Perlakuan } \\
\text { Kelompok Kontrol }\end{array}$ & 30 & 24 & 37 & & 33 & 27 & 37 & 0,002 \\
& 30 & 24 & 38 & & 30 & 24 & 38 & \\
\hline
\end{tabular}

Berdasarkan tabel 4. perbedaan perulaku responden tentang efikasi diri dan uji homogenitas pada kelompok perlakuan dan kelompok kontrol sebelum DSME dengan nilai $\mathrm{P}=0,454>\alpha(0,05)$, sedangkan setelah DSME dengan nilai $\mathrm{p}=0,002<\alpha$ $(0,05)$. Artinya ada perbedaan atau pengaruh DSME terhadap efikasi diri.

Tabel 5. Distribusi ResikoTerjadinya Ulcus Diabetik Responden tentang Uji Homogenitas pada Kelompok Perlakuan dan Kelompok Kontrol Pre dan Post

\begin{tabular}{lcccccccc}
\hline $\begin{array}{l}\text { Resiko terjadinya Ulcus } \\
\text { Diabetik }\end{array}$ & Mean & $\begin{array}{c}\text { Pre } \\
\text { Min }\end{array}$ & Max & P Value & Mean & $\begin{array}{c}\text { Post } \\
\text { Min }\end{array}$ & Max & P Value \\
\hline $\begin{array}{l}\text { Kelompok Perlakuan } \\
\text { Kelompok Kontrol }\end{array}$ & 7 & 3 & 11 & & 5 & 2 & 8 & 0,020 \\
& 8 & 4 & 12 & & 7 & 3 & 11 & \\
\hline
\end{tabular}

Berdasarkan tabel 5. perbedaan perilaku responden tentang resiko terjadi ulkus dan uji homogenitas pada kelompok perlakuan dan kelompok kontrol sebelum DSME dengan nilai $\mathrm{P}=0,329>\alpha(0,05)$, sedangkan setelah DSME dengan nilai $\mathrm{p}=0,020<\alpha(0,05)$. Artinya ada perbedaan atau pengaruh DSME terhadap pengetahuan tentang resiko ulkus.

\section{PEMBAHASAN}

Pengetahuan tentang perawatan pada kaki pasien DM terhadap resiko terjadinya ulkus diabetik pada pasien DM type 2 sebelum dan sesudah dilakukan DSME : Sasaran program diberikan kepada individu secara tatap muka. melibatkan salah satu anggota keluarga pada sesi kedua dari tiga sesi program intervensi edukasi. Dorresteijn (2010) melaporkan dalam intervention review, bahwa edukasi pada pasien Diabetes melitus tentang perawatan kaki dapat membantu mengurangi kaki diabetik dan amputasi, dimana kaki diabetik dan amputasi bukan saja menyebabkan kecacatan fisik dan kehilangan kualitas hidup, tetapi juga gangguan dari segi ekonomi.

Kepercayaan diri dalam melakukan perawatan kaki pada pasien DM type 2 sebelum dan sesudah dilakukan DSME : Efikasi diri adalah adalah sebuah teori kognitif yang dikembangkan Albert Bandura. Efikasi diri didefinisikan sebagai keyakinan individu akan kemampuannya untuk mengatur dan melakukan tugastugas tertentu yang dibutuhkan untuk mendapatkan hasil sesuai yang diharapkan. Efikasi diri membantu seseorang dalam menentukan pilihan, usaha untuk maju, serta kegigihan dan ketekunan dalam mempertahankan tugas-tugas yang mencaku kehidupan mereka. Efikasi diri mendorong proses kontrol diri untuk mempertahankan prilaku yang dibutuhkan dalam mengelola perawatan diri pada pasien (Norris, 2010).

Perilaku perawatan kaki pada pasien DM sebelum dan sesudah dilakukan DSME : Menurut Bandura dalam Passer dan Smith (2004), kunci 
penting bagaimana seseorang dapat mengatur hidup mereka adalah selfefficacy, keyakinan terhadap kemampuan mereka untuk menunjukkan perilaku yang diinginkan untuk mencapai tujuan. Orang yang mempunya self-efficacy yang tinggi mempunyai kepercayaan diri pada kemampuan mereka mengatasi rintangan dan mencapai tujuan mereka. Ada 4 determinan penting yang dapat mempengaruhi self-efficacy yaitu

pengalaman yang dimiliki, belajar dari hasil observasi, keikutsertaan emosi dan pendekatan verbal. (Passer \& Smith, 2004).

Pengaruh DSME terhadap resiko terjadinya Ulkus Diabetik pada pasien rawat jalan Diabetes Mellitus (DM) Type 2 : DSME adalah suatu proses berkelanjutan yang dilakukan untuk memfasilitasi pengetahuan, keterampilan, dan kemampuan pasien DM untuk melakukan perawatan mandiri. DSME merupakan suatu proses memberikan pengetahuan kepada pasien mengenai aplikasi strategi perawatan diri secara mandiri untuk mengoptimalkan control metabolik, mencegah komplikasi, dan memperbaiki

\section{DAFTAR RUJUKAN}

Funnell, M. M., et.al. 2008. National Standards for Diabetes Self-Managemen.

Norris, S. L., et.al. 2010. Increasing Diabetes SelfManagement Education in Community Settings. Am J Prev Med Vol. 22 (4S) : 3966.

Passer \& Smith, 2004. Psychology The Science of Mind \& Behavior. Mc Graw Hill : New York. kualitas hidup pasien DM. Tujuan umum DSME adalah mendukung pengambilan keputusan, perilaku perawatan diri, pemecahan masalah dan kolaborasi aktif dengan tim kesehatan untuk memperbaiki hasil klinis, status kesehatan, dan kualitas hidup. Hasil penelitian ini menunjukkan bahwa hipotesis (Ha) yang diajukan oleh peneliti diterima, yang berarti bahwa ada pengaruh DSME terhadap resiko terjadinya ulkus diabetik pada Pasien Rawat Jalan DM Type 2 di Wilayah Kerja Puskesmas Jalan Gedang Bengkulu tahun 2016.

\section{KESIMPULAN}

Hasil penelitian ini disimpulkan bahwa ada pengaruh Diabetes Self Management Education (DSME) terhadap resiko terjadinya Ulcus Diabetik (DM) type II di wilayah kerja Puskesmas jalan Gedang kota Bengkulu. Disarankan agar dapat menjadi masukan yang bermanfaat bagi tenaga kesehatan untuk dapat memberikan pengetahuan dan promosi kesehatan mengenai pengaruh DSME terhadap resiko terjadinya ulcus diabetik.

Pranadji, 2007. Perencanaan Menu Untuk Penderita Diabetes Mellitus. Jakarta: PT Penebar Swadaya.

Pusat Data dan Informasi PERSI, 2012. Faktor Lingkungan dan Gaya Hidup Berperan Besar Memicu Diabetes. Jakarta: Pusat Data dan Informasi PERS.

Sugiyono. 2011. Statistika Untuk Penelitian. Bandung: Alfabeta.

WHO, 2011. Pofil Kesehatan Dunia. 